\title{
Traumatic brain injury after a motor vehicle accident: Fact or "fantasy"?
}

\author{
D G E Caldicott, N Edwards
}

Gamma hydroxybutyrate (GHB) is a water soluble, naturally occurring, tetra-carbon molecule. It has intermittently found use as a hypnotic anaesthetic agent, in treatment for narcolepsy, as an anabolic agent, and more recently as a drug of abuse $e^{1-7}$ (also known as "fantasy", "GBH", etc (see box 1). Review of the literature refutes the suggestion that GHB is a safe "natural high", with a number of fatalities from overdose now reported. ${ }^{89}$ Deaths occur from profound respiratory and cardiovascular depression..$^{7-9}$ We report two cases of Fantasy overdose in association with a motor vehicle crash, the presenting symptoms of which prompted treating doctors to erroneously suspect serious intracranial pathology.

Box 1 Street synonyms for gamma
hydroxybutyrate
Fantasy
Phantasy
Liquid ecstasy
Liquid gold
Liquid X
Cherry Meth
Soap
GBH

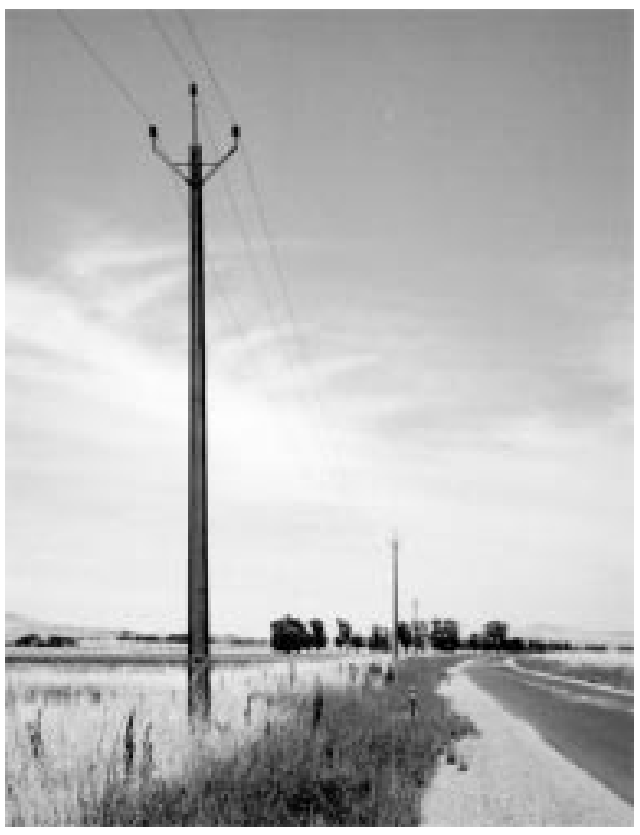

Figure 1 A stobie pole. Essentially two metal girders on either side of a concrete core, they were designed to support lines of electricity and communication to remote and rural southern Australia. Their longevity is inversely proportional to their contribution to road safety.

\section{Case report}

A 21 year old man and 20 year old woman were brought to the Trauma Unit of the Royal Adelaide Hospital after a motor vehicle crash.

The man was the restrained driver of a vehicle that had lost control and crashed into a stobie pole (see fig 1), at a speed in excess of $60 \mathrm{kph}$. There was at least $60 \mathrm{~cm}$ intrusion into the front passenger compartment. His GCS was estimated as $14(\mathrm{E}=4, \mathrm{~V}=4, \mathrm{M}=6)$ at the scene, where he was aggressive and combative, bleeding from a $5 \mathrm{~cm}$ midline laceration to his forehead. On arrival, he remained uncooperative, and required restraint. Further examination showed abrasions to his right shoulder, with an underlying fractured clavicle. He underwent computed tomography of his head, cervical spine and abdomen, all of which were normal.

The woman was the restrained front seat passenger, who was allegedly asleep at the time of the accident. On arrival of the ambulance crew, her GCS was estimated as $11(\mathrm{E}=4, \mathrm{~V}=2$, $M=5)$. In transit, her level of consciousness deteriorated to a GCS of $6(\mathrm{E}=2, \mathrm{~V}=2, \mathrm{M}=2)$, and she tolerated an oropharyngeal airway. She was endotracheally intubated for airway control on arrival in the emergency department. Examination revealed bilateral dilated and reactive pupils. She had an obvious "lap-belt" bruise across her lower abdomen, but without apparent other injury. After her intubation, she had a transient episode of bradycardia (50/ min), but maintained her blood pressure, with the bradycardia resolving spontaneously. She was taken for a CT scan of her head, cervical spine and abdomen, which were unremarkable other than an anterior crush fracture through the 10th thoracic vertebral body. She was admitted to the intensive care unit for observation overnight, and on weaning from sedation, rapidly regained consciousness.

Both patients subsequently admitted to having taken two "capfuls" of "fantasy" before the crash, with toxicological analysis of their urine by spectrophotometry, confirming the presence of GHB alone.

\section{Discussion}

GHB overdose is most often associated with the nightclub scene, and usually in the absence of associated trauma. Features of GHB are outlined in box 2 (A). The cases presented in this report demonstrate two important points. Firstly, in the context of trauma, concomitant GHB use can significantly blur the clinical presentation. GHB was almost certainly the cause of both patients diminished GCSs, and yet injuries incurred in the motor vehicle crash were originally thought responsible. Features that might cause suspicion of GHB use in an 
Box 2 (A) Pharmacological features of gamma hydroxybutyrate (GHB), with (B) features in the presentation of the unconscious patient that suggest GHB overdose

(A) PHARMACOLOGICAL FEATURES OF GAMMA HYDROXYBUTYRATE $^{715}$

White powder (sold in tablet or capsule form) or dissolved in water to form viscous clear fluid (sold by "capful").

Soapy/salty taste often masked by addition of artificial flavouring.

Onset of action 20 minutes after oral ingestion.

Half life 20-30 minutes.

Metabolised via Krebs cycle to carbon dioxide with respiratory clearance.

Biochemical precursors gamma butyrolactone and 1,4 butanediol metabolised to GHB.

(B) FEATURES IN THE PRESENTATION OF THE UNCONSCIOUS PATIENT THAT SUGGEST GHB OVERDOSE. $^{1-7}$

Historical features

History of previous/concurrent GHB use.

Attendance in the preceding six hours at a rave or night club

Features on examination

No evidence of head injury.

Equally reacting normal sized pupils.

Bizarre, athetoid posturing ("like a swimmer drowning").

Diminished or fluctuating GCS, the latter especially on noxious stimulation.

Unexplained bradycardia, bradypnoea and/or apnoea

Features on investigation

Normal blood sugar level

Normal CT of the head

unconscious patient are outlined in box 2 (B). Our female patient had dilated pupils, the reason for which was never elucidated. It should be emphasised that the diagnosis of GHB overdose in the presence of trauma is always one of exclusion.

Secondly, we believe this to be the first reported case in which the drug has played a causative part in a potentially lethal motor vehicle crash. This may be merely a reflection of the increasing prevalence of the drug, but should serve notice that further episodes such as this are likely to occur. The potential hazards associated with GHB use and driving have been suggested. ${ }^{10}$ The day after presentation, the driver reported that despite driving on a road he used regularly, while under the influence of GHB, he had been completely disorientated in time and place.

GHB is an increasingly important drug of misuse, with serious and potentially lethal effects in overdose. Its danger is compounded by the mistakenly perceived "safety" of its use by the drug abusing community. It is taken as a euphoriant, but there is a narrow window between the quantity required to achieve the desired effect, and that which can cause dangerous and potentially lethal side effects. ${ }^{8}$ It has increasingly been associated with "date rape". ${ }^{11}$ The intrinsic dangers of GHB misuse are already well described: it is perhaps surprising that it has taken so long for its secondary dangers, common to all sedating drugs of misuse, to become apparent. Legislation in the USA has recently been passed to make GHB and ketamine Schedule 1 drugs (that is, on a par with heroin and LSD).$^{12}$ Biochemical precursors of GHB (gamma butyrolactone and 1,4butanediol) are being marketed to subvert this legislation; their effects in overdose are almost identical to GHB. ${ }^{13}{ }^{14}$ All three compounds are easily made from cheap and readily acquired household ingredients, with recipes accessible from the internet. ${ }^{15}$ Unchecked, there is unlikely to be any diminution in the use of this category of drugs in the foreseeable future, and physicians have a responsibility to highlight the dangers of GHB and its related compounds to both users and legislators alike.

Our institution is currently conducting a trial of the use of physostigmine (originally used for reversal of elective GHB anaesthesia ${ }^{16}$ ) as a reversal agent for GHB overdose. We have had promising results ${ }^{17}$ with similar findings reported in the USA. ${ }^{18}$ It is possible that in trauma cases that have no apparent injury despite detailed physical examination and appropriate imaging physostigmine might have a role in reversing isolated GHB overdose.

Contributors

treated the patients, collated the information from the case notes, interviewed the patients, and performed the literature search. DC and NE co-wrote the manuscript and revisions. NE acts as guarantor for the paper.

Funding: none.

Conflicts of interest: none.

1 Ryan JM, Stell I. Gamma hydroxybutyrate-a coma inducing recreational drug. F Accid Emerg Med 1997;14:259-61.

2 Chin RL, Dyer JE, Sporer KA. gamma-hydroxybutyrate intoxication and overdose. [Letter]. Ann Emerg Med 1999; 33:476.

$3 \mathrm{Li} \mathrm{J}$ gamma-hydroxybutyrate intoxication and overdose. Li J. gamma-hydroxybutyrate intoxication
[Letter]. Ann Emerg Med 1999;33:475-6.

4 Kohrs FP, Porter WH. gamma-Hydroxybutyrate intoxicaKohrs FP, Porter WH. gamma-Hydroxybutyrate in
tion and overdose. Ann Emerg Med 1999;33:475-6.

$5 \mathrm{Li} \mathrm{J}$, Stokes SA, Woeckener A. A tale of novel intoxication: a review of the effects of gamma-hydroxybutyric acid with recommendations for management. Ann Emerg Med 1998; 31:729-36.

$6 \mathrm{Li} \mathrm{J}$, Stokes SA, Woeckener A. A tale of novel intoxication: seven cases of gamma-hydroxybutyric acid overdose. Ann Emerg Med 1998;31:723-8.

7 Chin RL, Sporer KA, Cullison B, et al. Clinical course of gamma-hydroxybutyrate overdose. Ann Emerg Med 1998; 31:716-22.

8 Ferrara SD, Tedeschi L, Frison G, et al. Fatality due to gamma-hydroxybutyric acid (GHB) and heroin intoxication. F Forensic Sci 1995;40:501-4.

9 Timby N, Eriksson A, Bostrom K. Gamma hydroxybutyrate associated deaths. Am F Med 2000;108:518-19.

10 Stephens BG, Baselt RC. Driving under the influence of GHB? f Anal Toxicol 1994;18:357-8.

11 Schwartz RH, Milteer R, LeBeau MA. Drug facilitated Schwartz RH, Milteer R, LeBeau MA. Drug facilitated
sexual assault ('date rape). South Med $\mathscr{f}$ 2000;93:558-61. 2 H.R. 2130 (Enrolled Bill, USA Constitution) Hillory J. Farias and Samantha Reid Date-rape Drug Prohibition Act of 2000 .

13 MMWR. Adverse events associated with ingestion of gammabutyrolactone-Minnesota, New Mexico, and Texas, 19981999. Morb Mortal Wkly Rep 1999;48:137-40.

14 Ingels M, Rangan C, Bellezo J, et al. Coma and respiratory depression following the ingestion of GHB and its precursors: three cases. $\mathcal{F}$ Emerg Med 2000;19:47-50.

15 Ropero-Miller JD, Goldberger BA. Recreational drugs. Current trends in the 90s. Clin Lab Med 1998;18:727-46.

16 Henderson RS, Holmes C McK. Reversal of the anaesthetic action of sodium gamma-hydroxybutyrate. Anaesth Intensive Care 1976;4:351-4.

17 Caldicott DGE, Kuhn M. Gamma hydroxybutyrate overdose and physostigmine: teaching new tricks to an old dose and physostigmine: teaching new
drug? Ann Emerg Med 2000;137:99-103.

18 Yates SW, Viera AJ. Physostigmine in the treatment of gamma hydroxybutyric acid overdose [published corrections appear in Mayo Clin Proc 2000;75:873]. Mayo Clin Proc 2000;75:401-2. 